\title{
Miscibility and Dynamic Mechanical Behavior of Blends with LCP'S
}

\author{
G. Gabellini and R.E. Suman Bretas*
}

Departamento de Engenharia Mecânica PUC/UFRGS, Caixa Postal 1429, CEP 90619-900 Porto Alegre RS, Brasil

* Departamento de Engenharia de Materiais UFSCar, Caixa Postal 676, CEP 13565-905 São Carlos SP, Brasil

\begin{abstract}
The main advantage of the "in situ" production of blends of thermoplastics with liquid crystalline polymers (LCP's) is viscosity reduction. In this work the phase behavior of blends of poly p-phenylene sulphide (PPS) with two different LCP's is presented. The LCP's are HX1000 (amorphous) and HX4000, crystalline, both from DuPont. The samples were prepared by injection molding and its dynamic mechanical properties were tested after annealing. It was observed that before annealing the blends were slightly miscible at all concentrations. It was also observed a plasticization of the PPS amorphous fraction by the LCP amorphous part. After annealing an increase of the PPS glass transition temperature was observed; the blends were also find to be immiscible. An average $\beta$-transition was observed at aproximately $76^{\circ} \mathrm{C}(\mathrm{HX1000})$ and at $88^{\circ} \mathrm{C}(\mathrm{HX} 4000)$; the glass transition temperatures were $160.48^{\circ} \mathrm{C}(\mathrm{HX} 4000)$ and $171.77^{\circ} \mathrm{C}$ (HX1000).
\end{abstract}

\section{INTRODUCTION}

Blends of engineering thermoplastics with liquid crystalline polymers (LCP's) have been widely studied due to: i) the synergistic mechanical behavior of these blends compared with the component polymers $[1,2]$; ii) the surging of new engineering thermoplastics matrixes, highly aromatic, but brittle, that requires reinforcement $[3,4]$; iii) the viscosity reduction promoted by the LCP's and iiii) the advantages relative to the processing of "in-situ"composites, like the lower energy comsumption. Poly (p-phenylene) sulphide (PPS) has been used mainly in the automotive and chemical industries due to its high thermal and chemical resistances. It has been reinforced with carbon and glass fibers in order to produce composites of outstanding mechanical properties; lately, however, it has been blended with LCP's in order to obtain the same composite behavior [5].

\section{EXPERIMENTAL}

\subsection{Materials}

Two LCP's were employed in order to produce the blends with the PPS; they were HX1000 and HX4000, both from DuPont. These LCP's are random terpolyesters made of terephthalic acid, hydroquinone and phenyl hydroquinone. The HX1000 has $\mathbf{M}_{\mathrm{w}}=35000 \mathrm{~g} / \mathrm{mol}$ and an "amorphous" behavior, while the $\mathrm{HX} 4000$ has a $\mathrm{M}_{\mathrm{w}}=40000 \mathrm{~g} / \mathrm{mol}$ and a "crystalline" behavior. The PPS used was Ryton V6 (Phillips Petroleum. Co) with $\mathrm{M}_{\mathrm{w}}=25300 \mathrm{~g} / \mathrm{mol}$ and $\mathrm{M}_{\mathrm{n}}=11000 \mathrm{~g} / \mathrm{mol}$. The blends were made by injection molding in an injection molding machine from Aurburg, with processing temperatures 
between : $320-350{ }^{\circ} \mathrm{C}$ and mold temperature between $50-60{ }^{\circ} \mathrm{C}$. The following blends, based on PPS/LCP weight composition were produced: 100/0, 80/20,60/40, 40/60, 20/80, 0/100. Annealing was also performed on the samples at $T=140^{\circ} \mathrm{C}$ during $48 \mathrm{~h}$.

\subsection{Dynamic mechanical analysis}

The dynamic mechanical thermal analysis was performed in a DMTA from Polymers Lab. The heat scanning was between 60 and $220^{\circ} \mathrm{C}$, at a heating rate of $2{ }^{\circ} \mathrm{C} / \mathrm{min}$, frequency of $10 \mathrm{~Hz}$, and strain of $64 \mu \mathrm{m}$, using a double cantilever geometry, on bending.

\section{RESULTS AND DISCUSSION}

The criteria for determining miscibility was the glass transition temperature $\left(T_{g}\right)$ change. $T g$ was assumed to be the temperature where the loss modulus, $E^{\prime \prime}$, has a maximum. Therefore, if the blends presented only one $\mathrm{Tg}$, then miscibility of the amorphous parts occurred. If two peaks were present, then imiscibility of the amorphous parts happened.Figure 1 and Figure 2 show typical DMTA scannings of the PPS/HX1000 (20/80) and PPS/HX4000 (20/80) blends, respectively. The maxima, each corresponding to the $\mathrm{Tg}_{1}$ of the PPS and to the $\mathrm{Tg}_{2}$ of the LCP's can be seen. Figure 3 shows the change of the $\mathrm{Tg}_{1}$ and $\mathrm{Tg}_{2}$ values as a function of the amount of $\mathrm{LCP}$, after annealing. As it can be seen, the values of $\mathrm{Tg}_{1}$ (PPS) in the PPS/HX1000 blends remain unchanged at approximately $114{ }^{\circ} \mathrm{C}$, while the $\mathrm{Tg}_{2}$ of the $\mathrm{HX} 1000$ had a slight decrease at high concentrations of PPS. Below PPS $60 \mathrm{wt} \%$, the values of $\mathrm{Tg}$ of the HX1000 remain constant. These results suggest partial miscibility. In the case of the PPS/HX4000 blends, it can be seen that the $\mathrm{Tg}_{1}$ of the PPS also remained unchanged at all concentrations; however, the $\mathrm{Tg}_{2}$ of the HX4000 showed a slight decrease up to a PPS 20 wt \% concentration, being constant after this concentration. This result also can be seen as a consequence of partial miscibility. It can observed that the analysis of these Tg's suggest that the LCP has no influence on the PPS. This can be due to the plasticizing effect that the PPS had on the LCP's. Small PPS molecules, rejected during the crystallization process, could diffuse to the low organized (amorphous) regions of the LCP, plasticizing it. Apart form the inherent experimental errors, however, we can conclude that these blends are imiscible or slightly miscible in the solid state. The analysis of the curves also shows the occurrence of the $\beta$-transition at $68.99{ }^{\circ} \mathrm{C}(\mathrm{HX1000})$ and $89.37{ }^{\circ} \mathrm{C}(\mathrm{HX} 4000)$. One possible source of this relaxation could be the relaxation of the lateral aromatic rings of the phenyl hydroquinone monomer.

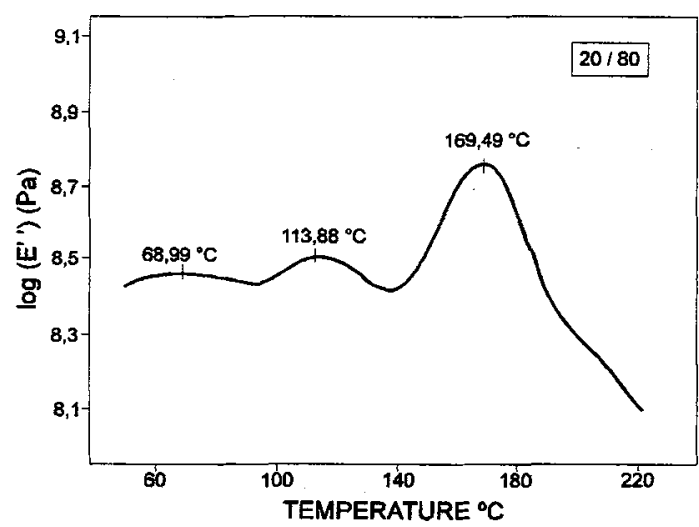

Figure 1. DMTA scanning of PPS/HX1000 blend

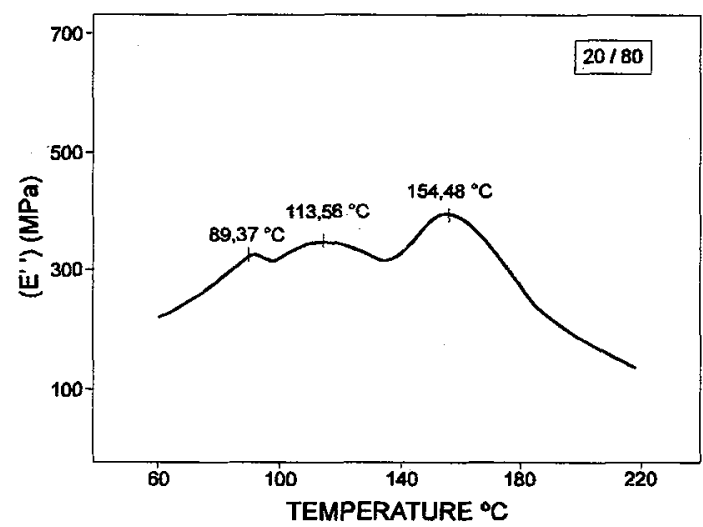

Figure 2. DMTA scanning of PPS/HX4000 blend 


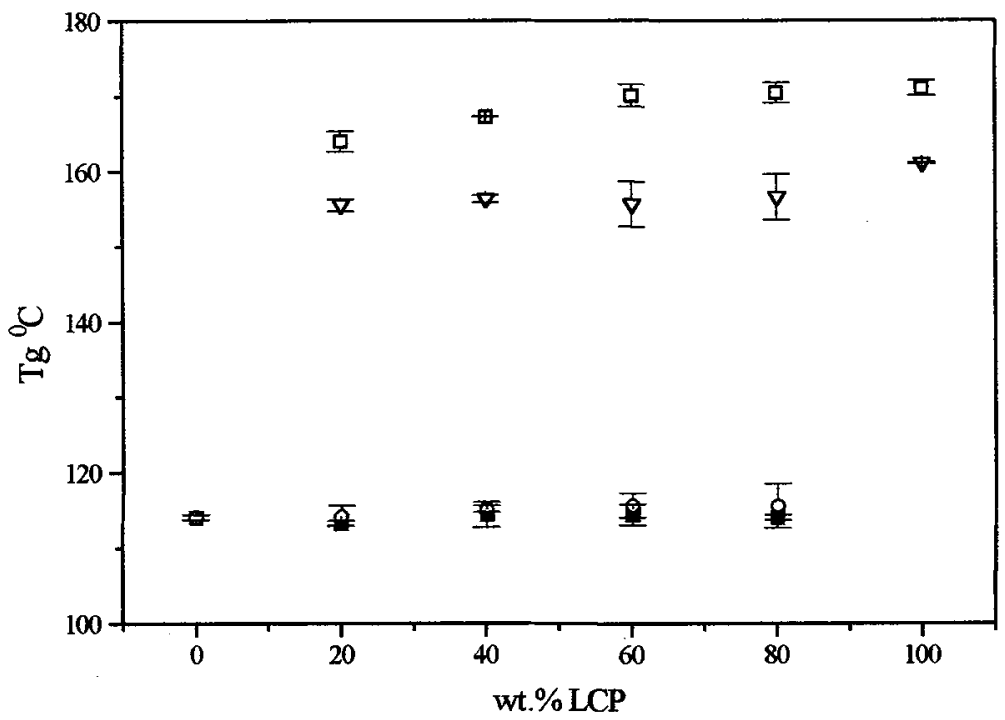

Figure 3. $\mathrm{Tg}_{1}$ (PPS) and $\mathrm{Tg}_{2}$ (LCP's) values as function of amount $\mathrm{LCP}$; where $\mathrm{Tg}_{1}$ of the PPS/HX1000( $\square$ ), $\mathrm{Tg}_{1}$ of the PPS/HX4000(O), $\mathrm{Tg}_{2}$ of the PPS/HX4000( $\left.\nabla\right)$ and $\mathrm{Tg}_{2}$ of the PPS/HX1000(D).

\section{CONCLUSIONS}

a. Blends of PPS and two LCP's, HX1000 and HX4000 were found, by DMTA, to be imiscible (or slightly miscible) in the solid state.

b. The PPS has a plasticizing effect on the LCP's.

c. A $\beta$-transition was found, that can be due to the relaxation of the lateral aromatic ring of the phenyl hydroquinone monomer.

\section{ACKNOWLEDGMENTS}

The authors thanks PUC/RS (Pontificia Universidade Católica do Rio Grande do Sul-Brasil) and FAPESP(Fundação de Amparo à Pesquisa do Estado de São Paulo-Brasil) 94/2317-9 for the financial support.

\section{REFERENCES}

[1] Blizard,K.G. and Baird, D.G. , Poly. Engi. Sci. 27 (9), (1987) 653.

[2] Isayev A. L. and Modie, M. , Polym. Comp, 8 (3) , (1987) 159.

[3] Pegoraro, M and Dilandro, L. "Plastics Rubber and Composites Processing and Applications" ,17, (1992) 269.

[4] Lucke, A. "Polyaryl Ether Ketones (PAEK) " Kunststoffe, 80 (1990) 1154.

[5] Gabellini , G., Moraes, M.B. and Bretas, R.E.S. J. Appl. Polym. Sci. 60 , (1996) 21. 